Peer review: This article has been subject to a double blind peer review process

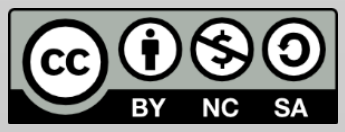

C Copyright: The Authors. This article is issued under the terms of the Creative Commons Attribution NonCommercial Share Alike License, which permits use and redistribution of the work provided that the original author and source are credited, the work is not used for commercial purposes and that any derivative works are made available under the same license terms.

\section{Ph.D. Researchers in a Changing World: A Self-Critical Reflection of the CES Conference 2017}

\author{
Alexander James Darracott* \\ Centre for Education Studies, University of Warwick \\ *Correspondence: A.J.Darracott@warwick.ac.uk
}

\begin{abstract}
The theme of this year's Centre for Education Studies Interdisciplinary Postgraduate Conference, now in its fifth year, is 'Education in a Changing World'. I attended the conference as a paper presenter and a conference attendee. My personal goals were to develop confidence as an oral presenter, seek professional development opportunities, and engage critically and reflectively with my work and the work of others. My relativist epistemological beliefs define knowledge as uncertain, context-bound, fallible, defeasible and therefore changeable, and are compatible with my personal goals. Both the goals and beliefs led to the adoption of knowledge co-constructor, communicator, and analyst roles. Beliefs, goals and adopted roles led to the identification of points of fallibility in my own knowledge and understanding of the phenomenon of interest. Therefore, I formed a perspective of conferences as enabling and facilitating knowledge construction between presenter and audience. Being reflective, critical, adaptable, creative, intuitive, flexible, and open minded are key attitudinal attributes of postgraduates, leading to positive conference experiences and increased self-awareness of own emerging identity as a social scientist. Increasing self-awareness of own identity is important for graduates, as on a broader scale this assists in keeping pace with an ever-changing world.

Keywords: reflections; conferences; professional development; thesis; presentation; attendee
\end{abstract}

\section{Introduction}

I attended the $5^{\text {th }}$ annual Warwick University Centre for Education Studies Interdisciplinary Conference 2017 as a paper presenter and as a doctoral researcher attendee from the Centre for Education Studies at the University of Warwick. The annual conference hosts a variety of graduate paper and poster presentations that showcase a diverse range of research designs, classroom teaching and learning approaches, and 
policy debates within a broadly defined theme. With the theme 'Education in a Changing World', this year's conference attracted a multitude of poster and paper presentations that illuminated the challenges that Education faces in an increasingly diverse world.

My paper presentation consisted of initial, tentative analysis of two short argumentative dialogues, each consisting of four participants. These took place in an online discussion forum known as The Student Room. One exchange referred to the impact of not being within the Schengen Zone, whilst the other referred to Quality and Quantity Control of EU Migration. The aim was to analyse the post-truth suggestion that there is a shift in the purpose of argumentative exchanges from seeking objective truth to defending propositions through appeals to emotion. The search for objective truth therefore does not go beyond the perspectives and emotions of the participant, with little consideration for or engagement with alternative perspectives and approaches as provided by other participants. Both exchanges form a much wider part of the data set for the Ph.D., the main objective of which is to develop a new theory that evaluates the quality of argumentative dialogues. Throughout the conference, I reflected deeply on the relationship between my epistemological beliefs and their impact on my experiences of the conference. I developed a series of questions based on the discussion of the epistemology of conferences by Skelton (1997). The questions were: what are my conceptions of knowledge? How do these conceptions impact on my engagement with conferences? How do the conference experiences contribute to thesis development and professional development planning?

This article is written, therefore, to provide critical, descriptive and explanatory accounts of my experiences as a paper presenter and a conference attendee at the Warwick University's Centre for Education Studies Interdisciplinary Conference 2017. My experiences shall be supported and critiqued through referencing relevant literature, and I shall explain how these experiences relate to thesis development and professional development planning. The rest of this article shall be organised as follows: reflective and critical accounts of my experience of being a paper presenter and reflective and critical accounts of my experience of being a conference attendee. A conclusion section situates my experiences within the wider field of graduate experiences, graduate and academic identity, and development of identity. 


\section{Attending as a Paper Presenter}

The $5^{\text {th }}$ annual Centre for Education Studies Interdisciplinary Conference 2017 was the first time I had ever presented a paper. Although initially I felt a little nervous, practicing the presentation multiple times not only reduced my nerves (Greene, 2015) but also assisted in developing step by step accounts of patterns and sequences found within the argumentative dialogues. Each account began with describing the type of content within the initial post. I then explained how the second participant initiated an argumentative exchange through offering either a challenge to a claim or an argument against the reasoning or evidence used. Then, I discussed how the exchanges were maintained through cycles of challenges, rebuttals and counter-arguments.

I created a PowerPoint with animations to assist with explaining the argumentative exchanges. Whilst Senese (2010: 4) argues that the aim of Power Point is to 'enhance a presentation not be a presentation,' I feel that PowerPoints assist with visualising the process of argumentative dialogues through animations and diagrams, which is not possible with verbal descriptions. Visual aids complemented my verbal descriptions and explanations, which I felt led to the reduction of audience misinterpretation of argumentative sequences and actions of argumentation. Explanations were constructed using non-technical language as it was assumed that not all members of the audience, despite their interest in the content, would understand technical terminology. My self-confidence improved through continuous practicing and development of suitable explanations of the step by step process of argumentative dialogues. During the presentation, I realised that I could deliver confidently if I practiced several times before the presentation.

The audience were largely welcoming of the presentation, and engaged critically through a question and answer session, and through providing written feedback to evaluate my presentation and to suggest improvements. Given the time restrictions, I adopted a suggestion from Gupta and Waismel-Manor (2006) to address and reflect upon the most significant and reoccurring themes. The most commonly occurring theme was the context of argumentative dialogue. Within this theme, suggestions referred to enhancing audience understanding of the argumentative process through increasing the scope of contextual descriptions. Their verbal suggestions were labelled as follows: descriptions of the online platform on which argumentative dialogues took place, justification of platform selection, and descriptions of the topic of the debates. Another theme, explanations and possible hypotheses of argumentative patterns, also occurred but not as frequently. The suggestions raised regarding the context were also 
raised in the written feedback with the following additional labels: firm definitions of argumentation, reasons for research, and the urgency and need for the research.

My epistemological beliefs enabled me to adopt the role of knowledge co-constructor. I used oral discussions and the written feedback to locate points of fallibility in my understanding of the phenomenon of interest. Understanding and knowledge were reformulated, leading to further development of the background and literature review chapters, and restructuring of any future presentations on argumentative dialogues. The extra background chapter sections are as follows: definitions of argument, argumentation and argumentative dialogue; topic of debate; urgency and need for the research; comprehensive comparisons between different online discussion platforms, and the nature of argumentative dialogues. The literature review shall further explore contextual differences of argumentative dialogues reported in empirical literature. Considerations shall include the impact of different debate questions and the nature and content of the topic upon argumentative dialogues. Additionally, for the discussion chapter, existing empirical findings regarding online argumentation shall be compared with the theory that emerges from the data as a form of theory validation and verification. Providing more detailed information about the context of my Ph.D. and argumentative dialogues within the thesis is expected to aid with reader understanding of the process of theory development. This greater understanding is expected to reduce the likelihood of misinterpretation and misunderstanding of findings.

Future presentations shall be restructured so that the audience is fully informed of the context of the argumentative dialogue before discussing and explaining the findings. Whilst it is expected that this shall reduce confusion about the context and nature of the argumentative dialogue, I would still welcome questions and debates about the importance of context.

In accordance with the six themes defined in the professional development framework at the University of Warwick, the experience of being a paper presenter contributed to professional development planning of the Personal Effectiveness, and Impact and Public Engagement themes. For both themes, restructuring the presentation and devising ways in which to present more complex argumentative dialogues and sequences shall arguably increase audience engagement. Presenting future findings as they emerge to audiences outside of academia would also increase my confidence, versatility and adaptability as an effective communicator. This is important, as being an effective communicator is increasingly becoming a part of the identity of a social 
scientist (Tomazou and Powell, 2007). I therefore intend to engage with formal communication courses provided by the University of Warwick and other external agencies in order to improve my Power Point and general communication knowledge, skills and techniques.

\section{Attending as a Conference Attendee}

My epistemological beliefs entail acceptance that critical and reflective engagement with conference presentations could illuminate points of fallibility in my knowledge, leading to the defeasibility and reconstruction of knowledge (Lehrer, 1990; Klein, 1971). Conferences, therefore, are perceived as facilitators of knowledge reconstruction (Wiessner et al, 2008; Vries and Pieters, 2008), critical reflection, and the critique, verification and validation of claims. The steps involved with my approach to engaging with the presentations of others, and conference experiences in general, were similar to the steps described by Wiessner et al (2008). These steps include: acknowledging and evaluating new knowledge and ideas; comparing new ideas with existing ideas; testing results of comparisons through conversations with presenters, and integrating new ideas and reformulating understanding of the phenomena of interest. Following this process, the reformulations assisted with further thesis development and professional development planning.

For the purposes of seeking to engage reflectively and critically, which led to a change in my understanding of research phenomena of interest, two out of the six presentations attended stood out. They were titled 'Education in a Changing World: The Investigation of the Theory-Practice issue for Acupuncture Education in the UK' and 'Research in Emotional Intelligence among Clergy and Future Directions'. Both presentations challenged and changed certain assumptions that I held. Firstly, that emotions were irrelevant because it was assumed that the nature of argumentative dialogues were inherently objective. Secondly, as my research is not situated in any physical educational establishment, theory-practice relationships were considered irrelevant. During the emotional intelligence presentation, the presenter explained that objective, rational, truth seeking discussions occur when participants are aware of their own emotions and manage them accordingly. Upon confirming ideas with the presenter, I have decided to consider the impact of emotions and the value of emotional intelligence when exploring and explaining patterns of argumentative dialogues. As for the theory-practice relationship presentation, part of the presentation provided a focus on the inadequacy of the relationship between theory and practice of acupuncture education in the UK. I then began to realise 
the importance of engaging with debates about the theory-practice relationship, leading specifically to considerations of the difference between theories of evaluating online argumentation and how evaluation takes place in practice. The presenter confirmed that all Ph.D. candidates in Education must be able to discuss how their theory or theoretical contributions can be applied in practice, and provide enhancements to existing practice.

These presentations have influenced potential directions of several thesis chapters. Regarding the literature review, emotional intelligence's relationship with argumentative dialogues and wider educational practice shall be critically analysed and evaluated. Further, analytical models related to analysis of arguments and knowledge construction shall be reconsidered with regards to measuring emotional content and its impact on dialogues. Also, theory-practice relationship literature shall be explored with regards to considering how existing evaluative models of argumentation have been applied in educational practices. As for data analysis, emotional content shall be coded, and relevant hypotheses shall be developed and tested against the continuously collected and analysed data.

With regards to my professional development planning, in accordance with the Professional Development Framework developed by Warwick University, focus shall be placed on categorical theme of Broadening Your Academic Skills. I shall investigate emotional intelligence by taking relevant courses, and critically and reflectively engaging with existing relevant literature. This is expected to lead to the emerging theory becoming a closer representation of the reality of argumentative dialogues.

\section{Concluding Thoughts on the Conference}

On a broader level, my experiences have encouraged me to ask the following question: how can conference experiences shape a graduate's emerging identity and be viewed as a valued part of their general graduate experiences? McAlpine et al (2009) classified doctoral experiences under three categories: formal, semi-formal, and informal. The authors argue that the purpose of exploring informal activities is to develop full understanding of doctoral experiences, and to understand informal activities as a means of 'contributing to students' sense of identity in relation to be(com)ing an academic' (McAlpine et al, 2009: 98). My experiences indicate conferences facilitate the occurrence of unplanned discussions with colleagues and the supervisor, as well as supporting the occurrence of serendipitous learning (Gadecki, 2001). 
Additionally, my experiences indicate that conferences facilitate knowledge sharing and construction (Wiessner et al, 2008; Vries and Pieters, 2008) and interactions with unfamiliar information (Haley et al, 2009). Conferences are therefore considered informal, but their informal nature should not negate their potential value as effective spaces and enablers of graduate reflective and critical engagement.

My conference experiences and my epistemological beliefs enabled me to become aware of my emerging and changeable identity as a social scientist. The experiences of being a paper presenter and a conference attendee led to the adoption of various, oscillating roles to suit the activity. As a paper presenter, I adopted the role of knowledge coconstructor and communicator, and as a conference attendee, I adopted the role of critical, reflective analyst. I felt a sense of being an academic through this cognitive, intellectual engagement with other people and with ideas, which reflects literature that explores graduate perceptions of becoming an academic (Jazvac-Mertek, 2009) and characteristics of being a Ph.D. graduate (Chenevix-Trench, 2006). Our identity and conceptions of ourselves as researchers, along with our sets of skills, knowledge, aptitudes, and attitudes are not absolute and certain. They are continuously changing and developing as we as graduates encounter different activities and experiences. Graduate identities, and academic identities in general, are dynamic and changeable relative to our perceptions and experiences within our wider research communities (Clegg, 2005).

Research has shown the importance of graduates possessing suitable mental skills, passion, appropriate state of mind, and a positive mindset to encounter positive conference experiences. In a study of faculty and graduate perceptions of graduate attitudes, Gardner et al (2006) developed the theme Habits of Mind. A graduate's habits of mind include holding a curious mind and being in a state of wonderment; of being autonomous, self-directed researchers; and, being receptive and reflective of feedback. Gardner et al (2006) also reported various skills that graduates should possess: analysis, evaluation, effective verbal and communication skills, and ability to converse with a variety of audiences. These skills are similar to characteristics of an open mind (Greene, 2015). Additionally, the findings of Haley et al (2009) indicate that if an attendee lacks the passion and interest of the theme of a conference, they are unlikely to gain any positive social or cognitive experiences. More broadly, these habits of mind and passion for research shall enable the graduate to experience any graduate activity or event positively and productively. Additionally, my experiences have shown the importance of epistemological beliefs. My epistemological beliefs enabled me to experience conferences as a platform for reflective and critical 
engagement, for effective knowledge sharing and synthesis, and for knowledge integration and reformation of conceptions.

Conferences, therefore, as an informal academic experience, provides effective social and cognitive spaces. Conferences facilitate the use and development of graduate skills and attitudes as long as we as academics engage ourselves socially as well as cognitively. Engaging with conferences critically and reflectively has enabled me to self-assess and make judgements on my current knowledge and skills. Self-assessments and the ability to make quality judgements on what we as researchers know has been highlighted as key doctoral skills (Baker, 2010). Essentially, graduates must be adaptable, creative, intuitive, flexible and open minded to the different social and cognitive encounters throughout their conference experiences. Graduate epistemological reflections should also be considered an important aspect of graduate practice and should form a part of the emerging identity of a researcher of the social sciences. Therefore, graduates should reflect on their epistemological beliefs, and the way in which these beliefs might impact on their goals and experiences of a conference. In order to increase effectiveness of their reflections and critical engagements, graduates must continuously seek opportunities to reflect upon and build their skills and knowledge as part of their professional development (Rudd et al, 2008; Vitae, 2008; Nerad, 2015).

More broadly, possessing and developing such skills and behaviours shall enable the graduate to become a fully-fledged social science researcher, and to be able to adapt to continuously changing political, economic, social and cultural contexts and climates. Further, developing selfawareness of identity increases a graduates' chance of identifying their place in a changing world, and how they can reposition themselves to take advantage of the opportunities that a changing world affords them as researchers. 


\section{References}

Baker, V.L. and L.R. Lattuca (2010), 'Development Networks and Learning, toward an Interdisciplinary Perspective on Identity Development during Doctoral study', Studies in Higher Education, 35 (7), 807-27

Clegg, S (2005), 'Theorising the mundane: The Significance of Agency', International Studies on Sociology of Education, 15 (2), 149-64

Chenevix-Trench, G (2006), 'What Makes a Good Ph.D. Student?', Nature, 441 (7090),

https://www.nature.com/naturejobs/science/articles/10.1038/nj7090$\underline{252 b}$,_accessed 18 July 2017

Gadecki, V.L (2001), 'Conventions, Reasons to Attend and Ways to Finance', Science Scope, 24 (6), 24-27

Gardner, S.K., M.T. Hayes, and X.N. Neider (2007), 'The Dispositions and Skills of a Ph.D. in Education Perspectives of Faculty and Graduate Students in One College of Education', Innovative Higher Education, 31, 287-99

Greene, M. (2015), A Postgraduate's Guide to Conference Attendance Survival Tips for Getting you Through the Process, https://www.rgs.org/NR/rdonlyres/E1AC77FD-610E-4B6B-ADC3C142750867E3/0/GreeneConferenceGuide.pdf, accessed 18 July 2017

Gupta, D. and I. Waismel-Manor (2006), 'Network in Progress: A Conference for Graduate Students', PS: Political Sciences and Politics, 39 (3), 485-90

Haley, K.J., C.A. Wiessner and E. Robinson (2009), 'Encountering New Information and Perspectives: Constructing Knowledge in Conference Contexts', The Journal of Continuing Higher Education, 57 (2), 72-82 Jazvac-Martek, M (2009), 'Oscillating Role Identities, the Academic Experiences of Educational Doctoral Students', Innovation in Education and Teacher International, 46 (3), 253-64

Klein, P. (1971), 'A Proposed Definition of Propositional Knowledge', The Journal of Philosophy, 73, 792-812

Lehrer, K. (1990), Theory of Knowledge, USA: Westview Press Inc McAlpine, L., M. Jazvac-Martek and N. Hopwood (2009)' Doctoral Student Experience in Education, Activities and Difficulties Influencing Identity Development', International Journal for Researcher Development, 1 (1), 97-109 
Nerad, M. (2015), 'Professional Development for Doctoral Students: What is it? Why now? Who does it?', Nagoya Journal of Higher Education, $15,285-318$

Rudd, E., M. Nerad, E. Morrison and J. Picciano (2008), Professional Development for Ph.D. Students, do they really need it? CIRGE Spotlight on Doctoral Education \#2. CIRGE, Seattle, WA: University of Washington

Tomazou, E.M. and G.T. Powell (2007), 'Look Who's Talking Too: Graduates Developing Skills through Communication', Nature Reviews Genetics, 8, 724-26

Senese, J.D. (2010), 'The Zen of Annual Meeting Attendance and Conferencing, Administration Publications and Research', Administration Publications and Research, 3. Available at http://scholarsarchive.jwu.edu/admin publications/3/, accessed $18^{\text {th }}$ July 2007

Skelton, A. (1997), 'Conferences, Conferences, Conferences?', Teaching in Higher Education, 2 (1), 69-72

Vitae (2008), Vitae Researcher Development Statement (RDS) https://www.vitae.ac.uk/vitae-publications/rdf-related/researcherdevelopment-statement-rds-vitae.pdf, accessed 18 July 2017

Vries, B.D. and J. Pieters (2008), 'Knowledge Sharing at Conferences', Education Research and Evaluation: An International Journal on Theory and Practice, 13 (3), 237-47

Wiessner, C.A., T. Hatcher, D. Chapman and J. Storberg-Walker (2008), 'Creating New Learning at Professional Conferences: an Innovative Approach to Conference Learning, Knowledge Construction and Programme Evaluation', Human Resource Development International, 4, 367-83

\section{To cite this article:}

Darracott, A.J. (2017). Ph.D. Researchers in a Changing World: A Self-Critical Reflection of the CES Conference 2017. Exchanges: The Warwick Research Journal, 5(1), 117-126. Retrieved from:

http://exchanges.warwick.ac.uk/index.php/exchanges/article/view/204 